\title{
Preparation of nanocomposite silver/kaolin with antibacterial properties
}

\author{
Balnur Baltabayeva, Aliya Ospanova ${ }^{1 *}$ and Zhanar Kubasheva \\ al-Farabi Kazakh National University, Almaty, Republic of Kazakhstan
}

\begin{abstract}
In this study, a nanocomposite based on kaolin from the Alekseevsky deposit (Kazakhstan), containing nano-silver particles, was synthesized. Kaolin has good physical and chemical properties and is an effective carrier for medicines. The synthesis of AgNPs/kaolin nanocomposites was carried out by chemical reduction. Impregnation of silver nanoparticles into silica matrix can prevent the agglomeration of mobile ions, and thereby preserve the antibacterial activity of the compound. The composition and structure of the resulting nanocomposite were studied using SEM/EDS analysis to study the morphology and elemental composition of natural and silver-modified kaolin, the specific surface was determined by the BET method, and functional groups were identified by IR spectroscopy. The resulting composite was tested for antibacterial activity against Gram-negative and Gram-positive bacteria (E.Coli, S. Aureus).
\end{abstract}

\section{Introduction}

According to an analysis of the Global burden of disease study, serious injuries cause about 1 in 10 deaths and lead to the annual death of more than 5.8 million people worldwide. Additionally, $20 \%$ of mortalities are observed in the presence of severe bleeding during the surgical procedure [1]. Drug resistance, formed from fungi and pathogenic bacteria, is the main cause of these victims. Despite the increasing knowledge about the pathogenesis of microbes and the use of modern treatment methods, the morbidity and mortality associated with microbial infections remain high [2]. There are several types of antimicrobials, that able to inhibit or exclude the growth of microorganisms, such as synthesized derivatives [3], antibiotics, antimicrobial peptides [4].

Currently, there is an urgent need to find new strategies and identify new antimicrobial agents from natural and inorganic substances to develop a new generation of drugs or agents to fight microbial infections. In practical medicine, inorganic antimicrobials based on silver and copper particles have been used since ancient times to treat microbial infections [5].

\footnotetext{
${ }^{1 * \text { Corresponding author: Ospanova a@mail.ru }}$
} 
Up to date, the majority of bacteria illustrate resistance towards antibiotics and the immune system, as a result of the ability to defend. Severe infectious which are formed from gram-negative Escherichia coli (E.coli) and gram-positive Staphylococcus aureus (S.aureus), is alarming, conventionally in a hospital environment and wound care, and may lead to the death of patients [6-8].

The importance of this research lies in the development of alternative drugs with silver nanoparticles which is capable of treating antibiotic-resistance due to the bactericidal properties of the Ag particles [9].

Silver (Ag) has received a resurgent interest for use in medicine, particularly in wound management [10]. It was found that $\mathrm{Ag}$ in wound dressings showed promising antibacterial effects $[11,12]$, with the nature of the carrier being an important factor. In medical practice, clay materials containing silver nanoparticles that interact with negatively charged bacterial cell membranes and damage them are a promising carrier for medicines [13,14]. Consequently, Ag-based nanocomposites are generally preferred in the topical treatment of wound infections, diabetic wounds [14], and especially in the prevention and control of infections caused by antibiotic-resistant bacteria [16,17].

In this regard, the establishment of optimal conditions for the production of new composite materials based on natural clay minerals containing promising bioactive silver nanoparticles is of theoretical and practical interest.

\section{Materials and methods}

\subsection{Characterization materials}

In this study, we used natural kaolin from the Alekseevsky deposit in the Kokshetau region, Kazakhstan. The solution of silver nitrate AgNO3 (Sigma Aldrich Saint Louis, MO 63103, USA) for synthesis silver nanoparticles. An ascorbic acid (LaborPharma) was used as a reduction agent. Polyvinyl alcohol MW - 47.00 (Sigma Aldrich Saint Louis, MO 63103, USA) for modification.

\subsection{Characteristics of instrumental methods}

The physicochemical characteristics of the obtained nanocomposites were studied by various methods. The structure and morphology of the surface, as well as the elemental composition of natural and modified kaolin, were captured on the scanning electron microscopy (SEM-EDS Quanta 3D 200i Dual system, FEI). The specific surface area was determined on the device Sorbtometer-M 220 (VCJSC, KATAKON, Novosibirsk).

The antibacterial analysis was carried out by the method of diffusion in agar-agar on a dense nutrient medium, by comparing the size of the growth inhibition zones of test microbes formed when testing solutions of certain concentrations. Staphylococcus aureus (S.aureus,) and Escherichia coli (E.coli) were used as a reference strain for testing antibacterial activity.

\subsection{The methodology of the experiment}

The natural kaolin was initially washed with distilled water and dried in an oven at $60^{\circ} \mathrm{C}$, then thermally treated at $500{ }^{\circ} \mathrm{C}$ for 5 hours. The obtained materials were acid-modified 1:10 (kaolin:acid) ratios of $10 \% \mathrm{H}_{3} \mathrm{PO}_{4}$ and $3 \mathrm{M} \mathrm{H}_{2} \mathrm{SO}_{4}$ in the thermostat for 5-6 hours at 
$100{ }^{\circ} \mathrm{C}$ and regularly added water to the glass to maintain a constant liquid level during the heating process.

The synthesis of the AgNPs/kaolin composite was carried out by impregnating a $2 \mathrm{~g}$ kaolin sample in an $\mathrm{AgNO}_{3}$ solution at a concentration of $1 \mathrm{~g} / \mathrm{L}(20 \mathrm{ml})$ at a rate of $2 \%$ silver relative to the mass of clay materials. The obtained suspensions were sonicated for 10 hours and then basified with $0.1 \mathrm{n} \mathrm{NaOH}$ to $\mathrm{pH}=9$. During the exchange reaction between $\mathrm{AgNO}_{3}$ and $\mathrm{NaOH}$, silver residues oxidize to silver oxides. Further reduction of the formed $\mathrm{Ag}_{2} \mathrm{O}$ was carried out with ascorbic acid $(3 \mathrm{~g} / \mathrm{L})$ and hydrogen peroxide $(30 \%)$. Fig. 1 illustrates the stepwise synthesis of $\mathrm{Ag}^{\mathrm{O}}$ clay composites.

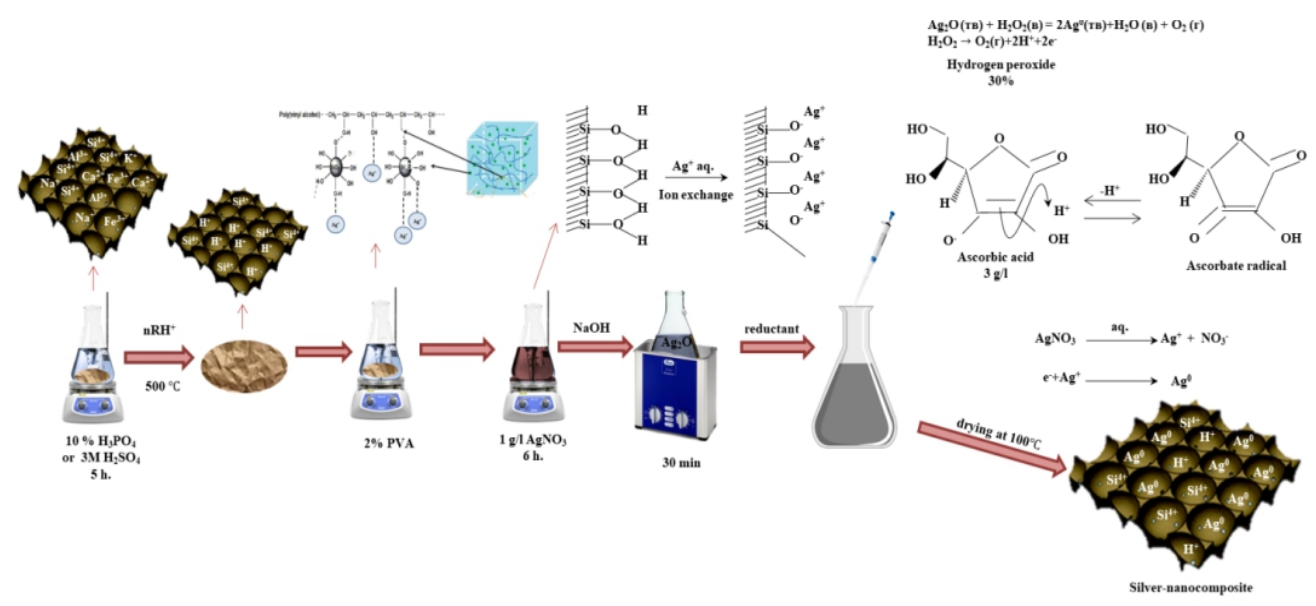

Fig. 1. Stages of synthesis of silver nanoparticles on the surface of kaolin.

\section{Results and discussion}

As is known, various reducing agents are used to obtain the desired sizes of nano-silver particles. In our research, we used ascorbic acid with moderate reducing activity. Since AgNPs are sensitive to aggregation, the natural mineral kaolin was tested as a stabilizing matrix to prevent the accumulation of silver particles. Due to the high percentage of $\mathrm{SiO}_{2}$ in $(80 \%)$ kaolin, this natural material can be used as a carrier for the delivery of antibacterial agents (AgNPs)

In the present study, sulfuric and phosphoric acids were used as acid leaching, followed by a comparison of two different modified surfaces. Not only does acid leaching improve the chemical surface of kaolin, but heat treatment is also highly desirable. Although heat treatment improves the compressive strength and chemical surface, further temperature increases cause the clay material particles to break down and condense, resulting in a reduced surface area. It is assumed that the crystal structure of aluminum changed from octahedral to tetrahedral coordination under the influence of heat treatment [17]. The gap between $\mathrm{Me}-\mathrm{O}(\mathrm{Fe}, \mathrm{Al})$ and $\mathrm{T}-\mathrm{O}(\mathrm{T}=\mathrm{Al}, \mathrm{Si})$ depends on the bond strength and proton substitution of the acid. Probably, protonation occurs following the electron-donor properties of oxygen, as a result, the bond between Me-O is destroyed and the metals move to the exchange position, which leads to the destruction of the crystal lattice. The most strongly bound cations $(\mathrm{Al}, \mathrm{Fe})$ in the crystal lattice displace other metals and together with protons of the activating acid create exchange acidity on the sample surface [18].

The elemental analysis of natural and modified kaolin is given in Table 1. 
Table 1. Elemental content of natural and modified kaolin (\%).

\begin{tabular}{|c|c|c|c|c|c|c|}
\hline Sample & $\mathrm{O}$ & $\mathrm{Al}$ & $\mathrm{Si}$ & $\mathrm{K}$ & $\mathrm{Ti}$ & $\mathrm{Ag}$ \\
\hline Natural kaolin & 54.95 & 19.78 & 22.68 & 1.61 & 0.98 & \\
\hline Kaolin $+\mathrm{H}_{3} \mathrm{PO}_{4}$ & 54.74 & 19.96 & 22.86 & 1.55 & 0.89 & \\
\hline Kaolin $+\mathrm{H}_{2} \mathrm{SO}_{4}$ & 54.96 & 19.94 & 22.75 & 1.51 & 0.84 & \\
\hline Kaolin $+\mathrm{H}_{3} \mathrm{PO}_{4}+\mathrm{Ag}$ & 54.74 & 19.34 & 22.31 & 1.53 & 0.89 & 1.22 \\
\hline Kaolin $+\mathrm{H}_{2} \mathrm{SO}_{4}+\mathrm{Ag}$ & 54.74 & 19.64 & 22.38 & 1.48 & 0.84 & 0.92 \\
\hline
\end{tabular}

The analysis of the IR spectra (Fig. 2) of natural and acid-modified kaolin indicates the main peaks characteristic of clay minerals.

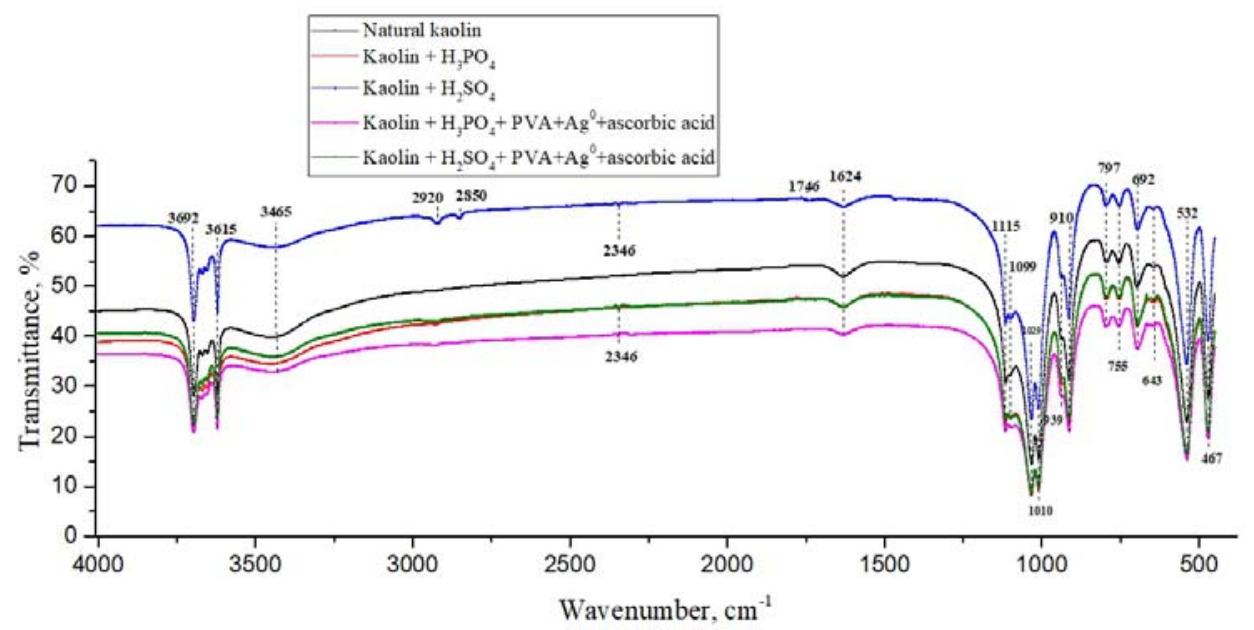

Fig. 2. IR spectra of natural, modified, and nanoparticle-containing silver in the kaolin structure.

Before and after the modification, there were minor changes in the IR spectra of the kaolin, which indicated a decrease in impurities and cation exchange metals. In the IR spectra of natural kaolin, the wide absorption band at $1099 \mathrm{~cm}^{-1}$ corresponds to the asymmetric stretching of Si-O-Si bonds. The resulting band at $\sim 1029 \mathrm{~cm}^{-1}$ is due to alternating stretching vibrations of $\mathrm{Si}-\mathrm{O}-\mathrm{Si}$ and $\mathrm{Al}-\mathrm{O}-\mathrm{Al}$ bonds [19]. The characteristic oscillation at $\sim 797 \mathrm{~cm}^{-1}$ refers to the $\mathrm{Me}-\mathrm{OH}-\mathrm{Me}(\mathrm{Me}=\mathrm{Fe}, \mathrm{Mg}, \mathrm{Al})$ bond [19]. while the peak at $\sim 532 \mathrm{~cm}^{-1}$ corresponds to the fluctuations of the $\mathrm{Al}^{4+}-\mathrm{O}-\mathrm{Si}$, bonds, where $\mathrm{Al}$ is present in the octahedral coordination. The band at $467 \mathrm{~cm}-1$ indicates the intraplane bending of the $\mathrm{Si}-\mathrm{O}$ and $\mathrm{Al}-\mathrm{O}$ bonds [20] originating from the separate tetrahedral. The wide bands at 3692 and $3615 \mathrm{~cm}^{-1}$ are caused by the stretching fluctuations of $\mathrm{OH}$ groups (Al-OH-Al) located at the edges of the kaolin surface. A narrow band at $\sim 1624 \mathrm{~cm}^{-1}$ is responsible for the bending $\mathrm{H}-\mathrm{O}-\mathrm{H}$ vibrations of the adsorbed water molecules [21]. The main changes in the IR spectra of the acid-modified kaolin (kaolin $+\mathrm{H}_{2} \mathrm{SO}_{4}$ ) are the appearance of new peaks of $2920,2850 \mathrm{~cm}^{-1}$. This is due to the carboxyl group presence on the kaolin surface. 
After treatment in acidic solutions, these peaks decreased due to the removal of metallic impurities from the matrix of amorphous silicon dioxide. In general, the base of the modified kaolin is probably constant, but it is likely that there were changes in the morphological structure of the modified sample.

The Ag metal peaks that appear at low wavenumber $\left(>400 \mathrm{~cm}^{-1}\right)$, were not detected due to the FTIR range $\left(4000-400 \mathrm{~cm}^{-1}\right)$, but the decrease in the intensity of the kaolin peaks indicates the successful application of nanoparticles to the structure of the composite material.

In Table 2, the specific surface area analysis shows that after modification with sulfuric acid, the surface of kaolin increases and has a larger surface area compared to modification with phosphoric acid. Moreover, it is obvious that after impregnation, the surfaces of silver composites have a smaller area compared to simply modified clay materials.

Table 2. Specific surface area of natural and modified kaolin.

\begin{tabular}{|c|c|c|c|}
\hline Sample & $\begin{array}{c}\text { Specific surface } \\
\text { area, } \mathrm{m}^{2} / \mathrm{g}\end{array}$ & $\begin{array}{c}\text { Specific pore } \\
\text { volume, } \mathrm{cm}^{3} / \mathrm{g}\end{array}$ & Average pore size, $\mathrm{nm}$ \\
\hline Natural kaolin & 13.453 & 0.006 & 1.713 \\
\hline Kaolin $+\mathrm{H}_{3} \mathrm{PO}_{4}$ & 33.166 & 0.012 & 1.713 \\
\hline Kaolin $+\mathrm{H}_{2} \mathrm{SO}_{4}$ & 54.46 & 0.028 & 1.713 \\
\hline Kaolin $+\mathrm{H}_{3} \mathrm{PO}_{4}+\mathrm{Ag}$ & 16.97 & 0.008 & 1.713 \\
\hline Kaolin $+\mathrm{H}_{2} \mathrm{SO}_{4}+\mathrm{Ag}$ & 28.29 & 0.016 & 1.713 \\
\hline
\end{tabular}

Changes in the morphology, structure, and surface of kaolin samples were studied by scanning electron microscopy, Fig. 3.

Kaolin is a layered structure consisting of a tetrahedral sheet $\left(\mathrm{SiO}_{4}\right)$ and an octahedral sheet $\left(\mathrm{AlO}_{6}\right)$. Figure $3 \mathrm{~A}$ shows the particles of flat plates with a thickness of about 1 micron, where flat sheets of pseudo-hexagonal shape are stacked on top of each other. There are individual fragments of scales with rough-sharp edges.
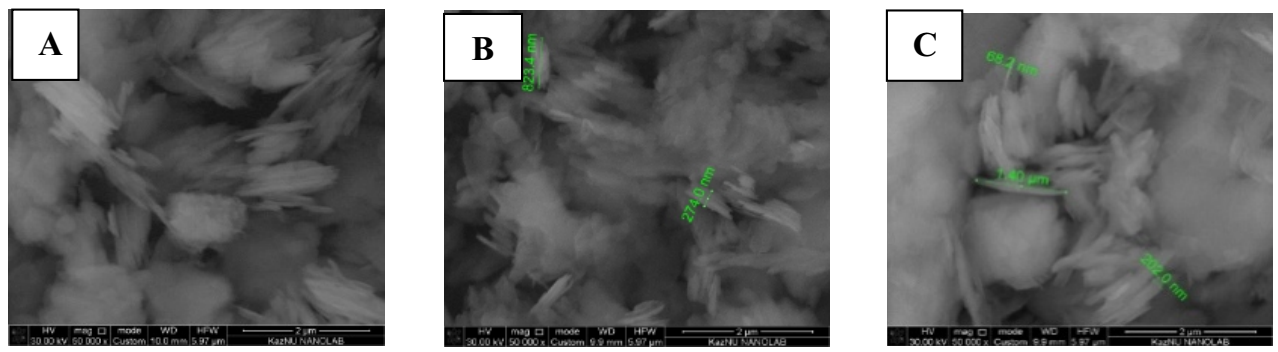

Fig. 3. SEM images of natural (A), modified with phosphoric acid (B) and sulfuric acid (C) kaolin.

After modification with phosphoric acid, the morphology and structure become smooth (Figure 3B). Flake fragments are less common, and an ordered stack of $\mathrm{SiO}_{4}$ and $\mathrm{AlO}_{6}$ sheets are present, but to a lesser extent. This may be due to the fact that phosphoric acid is a weak acid that does not destroy the structure of the clay mineral, but at the same time can remove impurities from some metals. When kaolin is modified with sulfuric acid, the 
morphology and structure become more uniform compared to modification with phosphoric acid, and the average thickness of the sheets is about 68-200 nm (Figure 3C). It should be noted that both types of modified kaolin served as a good matrix as carriers for silver nanoparticles and made it possible to obtain a new silver-containing composite material based on domestic raw materials. The obtained new composite materials based on Kazakhstan kaolin, containing deposited silver nanoparticles, showed good antibacterial activity on the growth of Gram-positive bacteria E.coli and S.aureus, Table 3.

Table 3. Results on the antibacterial activity of the nanosilver composites based on kaolin.

\begin{tabular}{|c|c|c|c|c|}
\hline \multirow[t]{2}{*}{ Samples } & \multirow{2}{*}{$\begin{array}{c}\mathrm{Ag}, \\
\text { wt } \%\end{array}$} & \multirow{2}{*}{$\begin{array}{c}\mathrm{m} \\
\text { antibiotic, } \\
\mathrm{g}\end{array}$} & \multicolumn{2}{|c|}{ Ratio of inhibition, $\%$} \\
\hline & & & E.coli & S.aureus \\
\hline $\begin{array}{c}\text { №1 } \\
\text { Kaolin }+ \\
\mathrm{H}_{3} \mathrm{PO}_{4}+\mathrm{Ag}\end{array}$ & 1.22 & $\begin{array}{c}0.012 \mathrm{~g} \\
(0.1464 \mathrm{mg} \\
\mathrm{Ag})\end{array}$ & & \\
\hline & & & $99,9 \%$ & $85-88 \%$ \\
\hline $\begin{array}{c}\text { №2 } \\
\text { Kaolin }+ \\
\mathrm{H}_{2} \mathrm{SO}_{4}+\mathrm{Ag}\end{array}$ & 0.92 & $\begin{array}{c}0.0175 \mathrm{~g} \\
(0.161 \mathrm{mg} \\
\mathrm{Ag})\end{array}$ & & \\
\hline & & & $99,9 \%$ & $99,9 \%$ \\
\hline
\end{tabular}

The antibacterial activity of the studied samples showed from 85 to $99 \%$ of bacterial death compared to the control samples. Despite the fact that the amount of silver in the structure of kaolin is from 1.22 to $0.92 \%$ relative to its mass, the composites have sufficient antibacterial activity and can be a good basis for promising dressings.

\section{Conclusions}

As a result of acid activation by sulfuric and phosphoric acids, optimal conditions for obtaining a new composite material containing silver nanoparticles were developed. Silver nanoparticles were obtained by reducing a solution of silver nitric acid with ascorbic acid under certain conditions and applying it to the carrier structure during the impregnation process. Given the low silver content in the composites, the antibacterial activity showed the death of both gram-positive bacteria S.aureus and gram-negative bacteria E.Coli. Therefore, the synthesized nanocomposite based on natural kaolin can be used as a carrier for antimicrobial agents.

This research has been funded by the Science Committee of the Ministry of Education and Science of the Republic of Kazakhstan (Grant No. AP09561734) 


\section{References}

1. G.H. Metrics, Global, regional and national age-sex specific mortality for 264 causes of death (1980-2016)

2. M. Kolář, K. Urbánek, T. Látal, Int. J. Antimicrob. Agents 17, 357 (2001)

3. I.B. Seiple, Z. Zhang, P. Jakubec et al., HHS Public Access 533, 338 (2019)

4. H. Jenssen, P. Hamill, R.E.W. Hancock, Clin. Microbiol. Rev. 19, 491 (2006)

5. D.F. Emerich, Expert. Opin. Biol. Ther. 5, 1 (2005)

6. D. Church, S. Elsayed, O. Reid, B. Winston, R. Lindsay, Clin. Microbiol. Rev. 19, 403 (2006)

7. R. Strohal, M. Schelling, M. Takacs, W. Jurecka, U. Gruber, F. Offner, J. Hosp. Infect. 60, 226 (2005)

8. S.L. Percival, K.E. Hill, D.W. Williams, S.J. Hooper, D.W. Thomas, Wound Repair Regen. 20, 647 (2012)

9. B.S. Atiyeh, M. Costagliola, S.N. Hayek, S.A. Dibo, Burns 33, 139 (2007)

10. D.A. Mendonca, R. Papini, P.E. Price, Int. Wound J. 3, 261 (2006)

11. M. Parani, G. Lokhande, A. Singh, A.K. Gaharwar, ACS Appl. Mater. Interfaces 8, 10049 (2016)

12. Nguyen V.H. et al. The Journal of Supercritical Fluids Preparation and antibacterial activity of silver nanoparticles-decorated graphene composites // J. Supercrit. Fluids. Elsevier B.V., 2012. Vol. 72. P. 28-35.

13. I. Sondi, B. Salopek-Sondi, J. Colloid. Interface Sci. 275177 (2004)

14. H. Qiu, F. Pu, Z. Liu, X. Liu, K. Dong, C. Liu, J. Ren, X. Qu, Nano Res. 12, 1 (2020)

15. J.S. Kim, E. Kuk, K. Nam et al., Nanomedicine 3, 95 (2007)

16. D.A. Mosselhy, H. Granbohm, U. Haynonen, Y. Ge, A. Palva, K. Nordstrom, S.P. Hannula, Nanomaterials 7, 261 (2017)

17. Y. Kato, K. Shimizu, N. Matsushita, T. Yoshida, H. Yoshida, A. Satsuma, T. Hattori, Phys. Chem. Chem. Phys. 3, 1925 (2001)

19. E. Srasra, F. Bergaya, J.J. Fripiat, Clays Clay Miner. 42, 237 (1994)

20. J. Madejová, M. Janek, P. Komadel, H.-J. Herbert, H.C. Moog, Appl. Clay Sci. 20, 255 (2002)

21. W.D. Keller, E.E. Pickett, Atlas of infrared spectroscopy of clay minerals and their admixtures (Elsevier, Amsterdam, 1977) 